\title{
Functional Thyroid Follicular Cells Differentiation from Human-Induced Pluripotent Stem Cells in Suspension Culture
}

\author{
Ayumi Arauchi ${ }^{1}$, Katsuhisa Matsuura ${ }^{1,2 *}$, Tatsuya Shimizu ${ }^{1}$ and Teruo Okano ${ }^{1}$ \\ 'Institute of Advanced Biomedical Engineering and Science, Tokyo Women's Medical University, Tokyo, Japan, \\ ${ }^{2}$ Department of Cardiology, Tokyo Women's Medical University, Tokyo, Japan
}

OPEN ACCESS

Edited by:

Rauf Latif,

Icahn School of Medicine

at Mount Sinai, USA

Reviewed by:

Gourav Roy Choudhury,

Texas Biomedical Research

Institute, USA

Hebao Yuan,

University of Michigan, USA

*Correspondence:

Katsuhisa Matsuura

matsuura.katsuhisa@twmu.ac.jp

Specialty section: This article was submitted to Thyroid Endocrinology, a section of the journal Frontiers in Endocrinology

Received: 02 March 2017 Accepted: 01 May 2017

Published: 22 May 2017

Citation:

Arauchi A, Matsuura K, Shimizu T and Okano T (2017) Functional

Thyroid Follicular Cells Differentiation from Human-Induced Pluripotent Stem Cells in Suspension Culture.

Front. Endocrinol. 8:103. doi: 10.3389/fendo.2017.00103
The replacement of regenerated thyroid follicular cells (TFCs) is a promising therapeutic strategy for patients with hypothyroidism. Here, we have succeeded in inducing functional TFCs from human-induced pluripotent stem cells (iPSCs) in scalable suspension culture. Differentiation of iPSCs with Activin A treatment produced Sox17- and FoxA2expressing definitive endodermal cells that also expressed thyroid transcription factors Pax8 and Nkx2-1. Further treatment with thyroid-stimulating hormone (TSH) induced TFCs expressing various types of thyroid proteins including TSH receptor, sodiumiodide symporter, thyroglobulin, and thyroid peroxidase. Interestingly, differentiated cells secreted free thyroxine in vitro. These results indicate successful differentiation of human iPSCs to functional TFCs that may enable us to fabricate thyroid tissues for regenerative medicine and disease models.

Keywords: induced pluripotent stem cells, differentiation, 3D-cell culture, thyroid transcription factor, thyroid follicular cells

\section{INTRODUCTION}

Although thyroidectomy is widely applied for patients with various types of thyroid diseases, such as thyroid nodular diseases, goiters, and Basedow's disease, subsequent hypothyroidism remains a highly undesirable problem (1). Currently, patients with thyroid hormone shortage subsequent to thyroidectomy require thyroid hormone replacement therapy via oral administration for life. However, as doses are often adjusted according to endogenous hormone levels, patients are not always maintained in euthyroid condition. Therefore, treatment strategies to physiologically supplement thyroid hormone levels are ideal, with thyroid replacement using regenerated tissue expected to be an alternative and radical treatment.

Thyroid tissue is constructed from two types of cells, thyroid follicular cells (TFCs) and parafollicular cells (C-cells) (2). TFCs primarily regulate thyroid functions such as production and secretion of thyroid hormones, including $\mathrm{T}_{3}$ and $\mathrm{T}_{4}$. A monolayer of TFCs organizes follicles into honeycomblike structures that produce thyroglobulin (TG), which is modified with iodine into thyroid hormone (2). We previously demonstrated fabrication of the thyroid gland in vivo using cell sheet tissue engineering of rat thyroid cells (3-5). Fabricated thyroid cell sheets showed follicle structures on the temperature-responsive culture dishes in vitro. Moreover, when transplanted subcutaneously into a rat total thyroidectomy model, regenerated tissues with structures resembling the thyroid gland's spherical follicular cell layer (with collide inside) and parafollicular cells were observed. 
Further, serum concentration of free triiodothyronine $\left(\mathrm{T}_{3}\right)$ and thyroxine $\left(\mathrm{T}_{4}\right)$ recovered to levels similar to that of littermates. These findings indicate the integration of suitable cell sources and appropriate tissue engineering technologies potentiates fabrication of functional thyroid tissues to replace thyroid hormone (5).

While it is ideal to transplant a patient's own thyroid cells after isolating and expanding these cells from tissues resected during surgery, transplantation of over 100 million TFCs is calculated from previous reports in animals (5) to be necessary to supplement reduced thyroid hormone levels observed with hypothyroidism. Furthermore, this strategy might not be suitable for patients with malignant tumors owing to the recurrent risk. Recent advancement of reprogramming technologies has enabled generation of patient-derived induced pluripotent stem cells (iPSCs) that may overcome cell source issues in terms of both quality and quantity $(6,7)$. Additionally, the development of three-dimensional (3-D) suspension culture strategies facilitates generation of large amounts of differentiated cells, such as iPSC-derived cardiomyocytes and pancreatic b cells, within a single production run. Recently, we developed a scalable 3-D suspension culture system for human iPSCs and succeeded in producing over 100 million human cardiomyocytes, which enabled fabrication of functional cardiac tissues in vitro and in vivo $(8,9)$. However, it remains unclear whether human iPSCs can be differentiated into functional TFCs using scalable suspension culture methods.

Members of the thyroid transcription factor (TTF) family include paired box protein 8 (Pax8) and homeobox protein (Nkx2-1, also known as TTF-1) (10), which are known to be essential for thyroid gland development and morphogenesis (11-13). Complete absence of thyroid follicles has been reported in mice lacking Pax8 or Nkx2-1 genes (11-13). Meanwhile, overexpression of Pax8 and Nkx2-1 in mouse and human embryonic stem cells (ESCs) or PSCs is reportedly enough to drive TFCs differentiation into thyroid hormone-secreting cells that recover function of hypothyroidism models in vivo (14-16). Antonica et al. succeeded in generation of functional TFCs from the Pax8 and Nkx2-1 co-expressed mouse ESCs with Matrigel-supported 3D culture stimulated by thyroid-stimulating hormone (TSH) (14), and also Ma et al. reported the differentiation both of mouse and human PSCs into the functional follicle structural TFCs by Activin A and TSH stimulation $(15,16)$. Furthermore, as these transcription factors directly regulate expression of thyroidspecific genes including TG, thyroid-stimulating hormone receptor (TSHR), thyroid peroxidase (TPO), and sodium/iodide symporter (NIS) (17), specific expression levels of Pax8 and Nkx2-1 might be sufficient for functional TFC differentiation. However, it remains unclear whether these defined factors can induce sufficient upregulation of Pax8 and Nkx2-1 expression to further TFC differentiation.

This study demonstrated direct differentiation of human iPSCs into functional TFCs using defined factors in a scalable suspension culture method. Treatment with Activin A and TSH induced Pax8- and Nkx2-1-expressing cells in cell aggregates through a definitive endoderm intermediate. Furthermore, $P A X 8$ - and NKX2-1-expressing cells also expressed TG, TSHR, $T P O$, and NIS and secreted free $\mathrm{T}_{4}$ in vitro.

\section{MATERIALS AND METHODS}

\section{Growth and Maintenance of Human iPSCs}

Human iPSCs (253G1) were purchased from RIKEN. These cells were generated from human skin fibroblast by retroviral transduction of Oct3/4, Sox2, Klf4 (7), and maintained on a feedercell layer of mitomycin C-treated mouse embryonic fibroblasts (ReproCELL). Subculture passages were performed every 2 days at a 1:3 ratio in Primate ES Medium (ReproCELL) supplemented with $5 \mathrm{ng} / \mathrm{ml}$ basic fibroblast growth factor (ReproCELL). The culture medium was changed every day. Undifferentiated state was assessed routinely and before starting differentiation experiments by qPCR for Nanog, Oct-4 gene expression.

\section{Differentiation of Human iPSCs into Definitive Endoderm and TFCs}

First, we collected human iPSCs using a dissociation solution (ReproCELL) and suspended these cells into small aggregations. To aggregate, cells were harvested in mTeSR1 (Stemcell Technologies) with $10 \mu \mathrm{M}$ Y-27632 (Wako) and then stirred in a 30-ml volume-standardized bioreactor (ABLE Co.) for 2 days to form embryoid bodies (EBs). These EBs were then cultured for 3 days to induce definitive endoderm in StemPro-34 Media (Gibco) supplemented with StemPRO-34 Nutrient Supplement (Gibco), $400 \mu \mathrm{M}$ monothioglycerol (Sigma-Aldrich), $2 \mathrm{mM}$ L-Glutamine (Gibco), $50 \mu \mathrm{g} / \mathrm{ml}$ L-Ascorbic acid (Sigma-Aldrich), $100 \mathrm{ng} / \mathrm{ml}$ Activin A (R\&D systems), and on the first day only, $3 \mu \mathrm{M}$ CHIR99021 (Stemcell Technologies). Later, differentiation of EBs into TFCs was performed in endodermal medium without Activin A and with addition of the following nutrients: $1 \mathrm{mU} /$ $\mathrm{ml}$ bovine thyrotropic hormone (TSH) (Sigma-Aldrich), $50 \mathrm{ng} /$ $\mathrm{ml}$ recombinant human IGF-1 (Invitrogen), $10 \mu \mathrm{g} / \mathrm{ml}$ human recombinant insulin (Gibco), $6 \mu \mathrm{g} / \mathrm{ml}$ transferrin (Roche Applied Science) and $10^{-8} \mathrm{M}$ hydrocortisone (Calbiochem). Samples were collected on culture days $0,5,10,15,20$, and 25 . The medium was changed every other day.

\section{RNA Extraction and Real-time Reverse- Transcription Polymerase Chain Reaction (RT-PCR)}

To extract total RNA from EBs, an RNeasy ${ }^{\circledR}$ Plus Mini Kit (Qiagen) was used according to the manufacturer's protocol. cDNA synthesis was completed using a First-Strand cDNA Synthesis Kit (OriGene). Primer pairs and TaqMan MGB probes were designed for human SOX17 (Hs00751752_s1), FOXA2 (Hs00232764_m1), PAX8 (Hs01015257_g1), NKX2-1 (Ttf-1) (Hs00968940_m1), SLC5A5 (Nis) (Hs00166567_m1), TPO (Hs00892519_m1), TG (Hs00174974_m1), TSHR (Hs01053846_m1), and GAPDH (Hs00751752_s1) using a TaqMan gene expression assay (Applied Biosystems). RT-PCR was performed with $\mathrm{SYBR}^{\circledR}$ Green qPCR Master Mix (Applied Biosystems) and a StepOnePlus ${ }^{\mathrm{TM}}$ Realtime PCR System (Applied Biosystems). mRNA expression levels were analyzed in real time using the $2^{-\triangle \Delta C T}$ method normalized to $G A P D H$ expression as an internal control. Results were confirmed in three different samples $(n=3)$ for each time-dependent collection and all samples were tested in duplicate. 


\section{Flow Cytometry}

Collected EBs were washed with PBS (Sigma-Aldrich) and treated with $0.25 \%$ Trypsin-EDTA (Thermo Fisher Scientific) for $10 \mathrm{~min}$ at $37^{\circ} \mathrm{C}$ to disperse EBs into single cells. Following 2\% paraformaldehyde (PFA) fixation for $10 \mathrm{~min}$, single cells were fixed with 4\% PFA for $20 \mathrm{~min}$ and then harvested as a cell pellet by centrifugation at $430 \times g$ for $3 \mathrm{~min}$. Cells were incubated in blocking solution, consisting of $5 \%$ donkey serum and $0.1 \%$ Triton $^{\mathrm{TM}}$-X (Sigma-Aldrich) in PBS, for $30 \mathrm{~min}$ at room temperature and then divided into several tubes for staining. Cells were then incubated with primary antibodies at $4^{\circ} \mathrm{C}$ overnight. For our double-immunostaining procedure, goat anti-human Sox17 (AF1924 R\&D systems, 1:50) and rabbit anti-human FOXA2 conjugated to Alexa Fluor ${ }^{\circledR} 647$ (ab193879 Abcam, 1:200), or goat anti-human Pax8 (ab13611 Abcam, 1:200) and rabbit anti-human TTF-1 (ab76013 Abcam, 1:200) were used. For negative controls, normal goat IgG (sc2028 Santa Cruz Biotechnology), normal rabbit IgG (sc2027 Santa Cruz Biotechnology), and normal rabbit IgG conjugated to Alexa Fluor 647 (sc24647 Santa Cruz Biotechnology) were applied.

Finally, following three rinses with blocking solution, cells were incubated for $60 \mathrm{~min}$ at room temperature with secondary antibodies, including anti-goat Alexa 488 (705546147 Jackson ImmunoResearch, 1:200), anti-rabbit Alexa 594 (711586152 Jackson ImmunoResearch, 1:200), and Hoechst 33342 (H3570 Thermo Fisher Scientific, 1:500) nuclei stain. Prepared samples were evaluated using a Gallios (Beckman Coulter) and obtained results were analyzed by Kaluza (Beckman Coulter).

\section{Immunostaining}

Embryoid bodies were washed with PBS and fixed with 4\% PFA for $20 \mathrm{~min}$. Cells were incubated for $60 \mathrm{~min}$ at room temperature with blocking solution, consisting of 5\% donkey serum and $0.1 \%$ Triton-X in PBS, and divided into 1.5- $\mathrm{ml}$ microtubes for staining. EBs were incubated with primary antibodies at $4^{\circ} \mathrm{C}$ overnight and then rinsed three times with blocking solution before applying secondary antibodies for $60 \mathrm{~min}$ at room temperature. Primary antibodies against Sox17, FoxA2, Pax8, and TTF-1, as well as negative control and secondary antibodies, employed the same materials and dilution as used for flow cytometry. To identify thyrocytes, thyroid-specific antibodies including mouse anti-human TSHR (ab6044 Abcam, 1:50), mouse anti-human NIS (ab17795 Abcam, 1:50), rabbit anti-human TG (ab156008 Abcam, 1:50), and normal mouse IgG (sc2025 Santa Cruz Biotechnology) was applied for the negative controls. EBs were washed with PBS, spread on the surface of a glass slide, and then mounted with GelMount ${ }^{\mathrm{TM}}$ (Biomeda). Finally, all of the immunostained samples were examined under confocal microscope (Olympus).

\section{Enzyme-Linked Immunoassay (ELISA)}

Medium was sampled at the end point of human iPSC differentiation. To measure the level of human-free thyroxine (free $\mathrm{T}_{4}$ ) in medium, a Human-Free Thyroxine ELISA Kit (MyBioSource) was employed according to the manufacturer's protocol. Results were confirmed in three different samples $(n=3)$ for each collected medium and without cell-cultured medium. All samples were tested in duplicate.

\section{Statistical Analysis}

Values are expressed as mean \pm SD. Data were plotted using Microsoft Excel, and statistical analyses were performed using ANOVA, post hoc Tukey's test and unpaired Student's $t$-test. Values of $p<0.05$ were considered statistically significant.

\section{RESULTS}

\section{Differentiation of Human iPSCs into Definitive Endoderm}

As thyroid development is known to progress via definitive endoderm (18-20), human iPSCs were cultured in medium supplemented with Activin A for endodermal differentiation following formation of cell aggregates in a stirred vessel (Figure 1A). After 2 days in undifferentiated culture conditions, spherical agglomerations increased in size to approximately $100 \mu \mathrm{m}$ (Figure 1B). The size of these (EBs) increased to more than $200 \mu \mathrm{m}$ in diameter (Figure 1B) after 5 days (day 3 of differentiation). To confirm endodermal differentiation, expression of Sox17 and FoxA2 mRNA was evaluated with RT-PCR analysis. Compared with before differentiation (day 0), both Sox17 and FoxA2 expression significantly increased on day 5, and thereafter decreased until day 20 (Figure 1C). Flow cytometric analysis revealed that more than $45 \%$ of cells expressed both Sox 17 and FoxA2 on day 5 (Figure 1D) and these proteins were co-expressed in nuclei within cell aggregates (Figure 1E). Accordingly, these results indicate successful definitive endodermal differentiation.

\section{Differentiation of TFCs}

Thyroid-stimulating hormone is reportedly critical for thyroid development and as TSHR mRNA expression was observed in cells on day 5 (Figures 3A,B), we examined whether cells had the potential to differentiate into TFCs at this time point with TSH treatment (Figure 1A). Pax 8 mRNA expression levels and the percentage of Pax8-expressing cells were not different between day5 and day20 (15 days with TSH treatment), suggesting that TSH might not directly affect Pax8 expression. As Pax8 is known to be an essential transcription factor not only for thyroid development but also kidney and urogenital development, we next examined expression of $\mathrm{Nkx} 2-1$, another essential transcription factor for thyroid development. Nkx2-1 mRNA was slightly expressed on day 5 and obvious at day 20, with about $15 \%$ of cells positive for Nkx2-1. Although Nkx2-1 is also known to be critical for lung development, almost all Nkx2-1-expressing cells also expressed Pax8 (Figures 2B,C), suggesting that these Pax8 and Nkx2-1 co-expressing cells might be thyroid progenitor cells. These findings suggest continuous treatment with TSH promotes thyroid differentiation in suspension cultures through mainly promote the expression of Nkx2-1.

\section{Expression of Thyroid-Specific Markers and Secretion of Free $\mathrm{T}_{4}$ in Differentiated TFCs In Vitro}

One report indicates the overexpression of Pax8 and Nkx2-1 induces expression of TSHR and NIS in human ESCs even before 
A
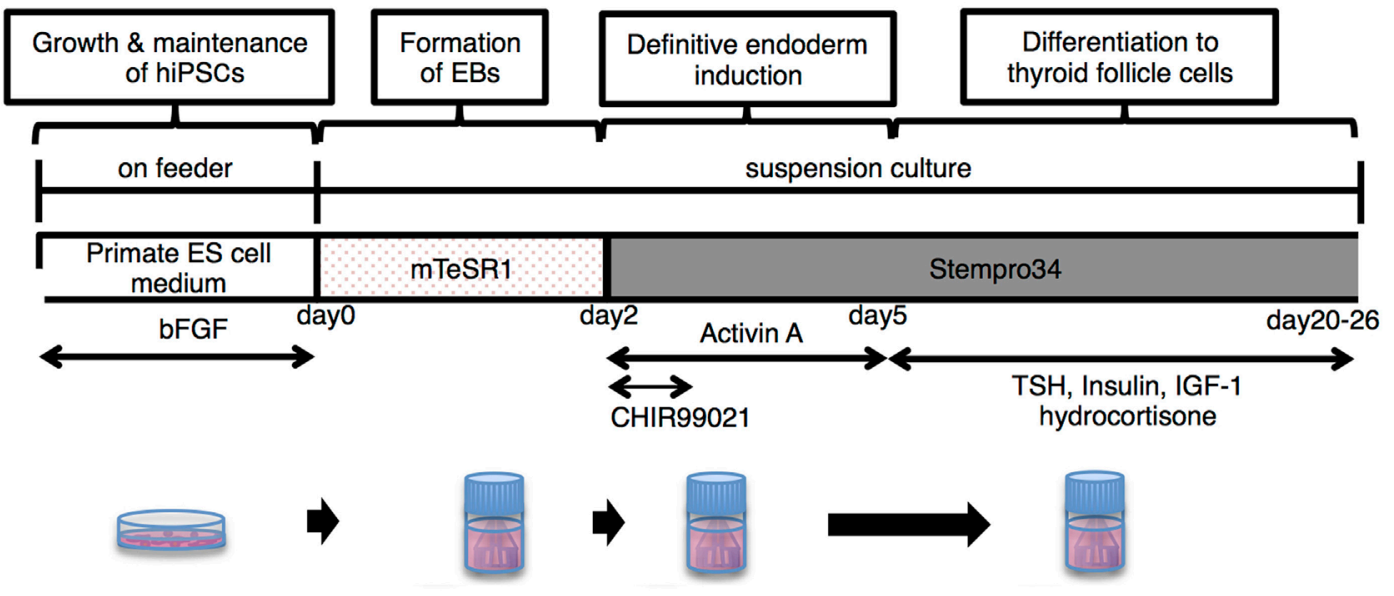

B

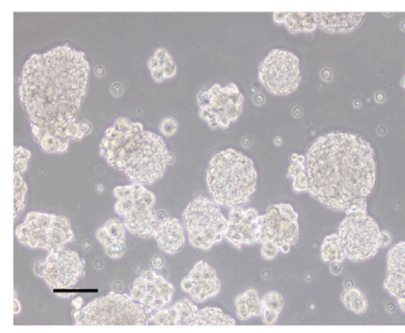

Culture day 2

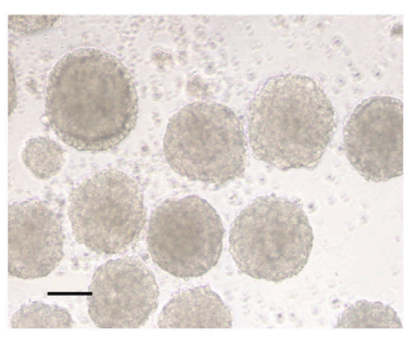

Culture day 5

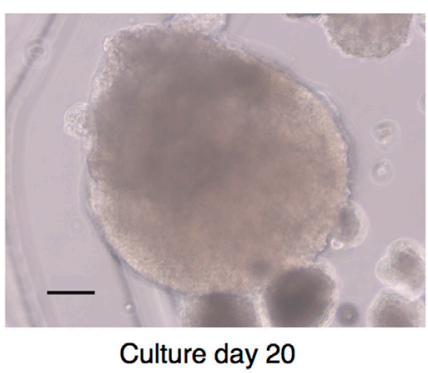

Culture day 20
C $\quad \operatorname{sox} 17$

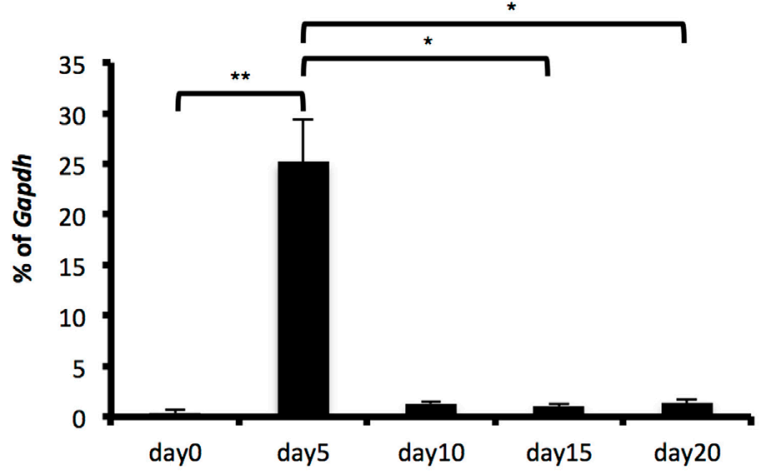

FoxA2

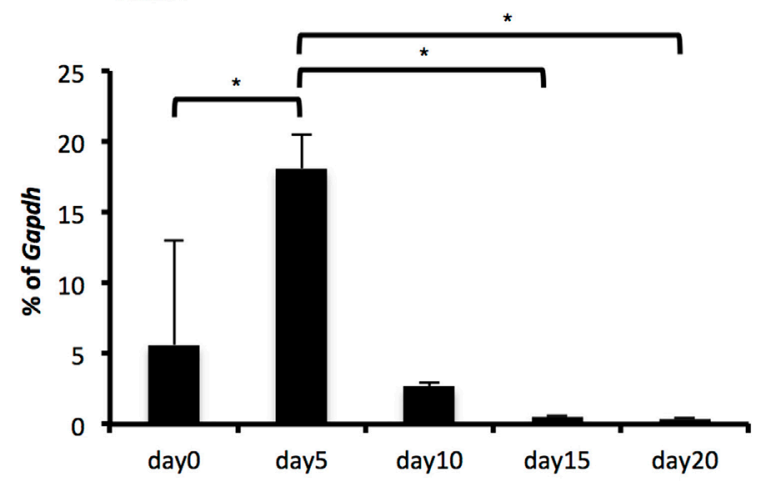

D

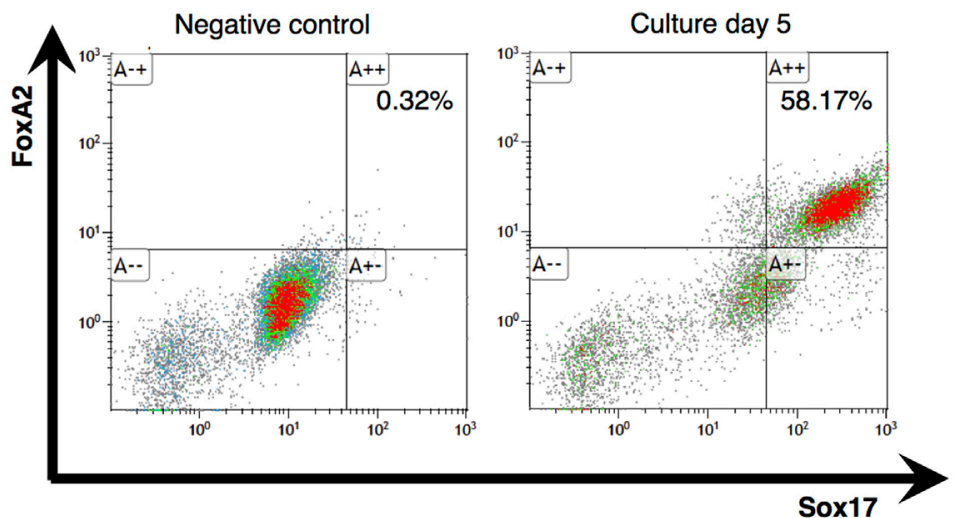

Culture day 5

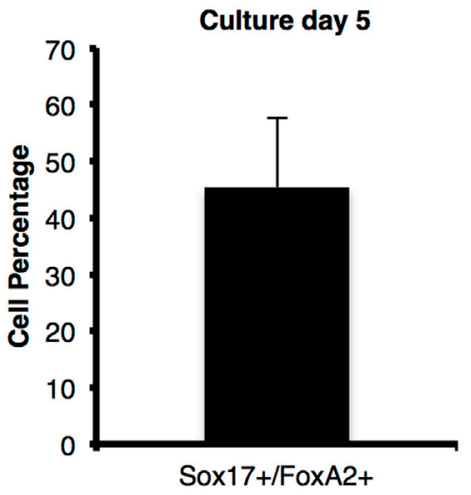



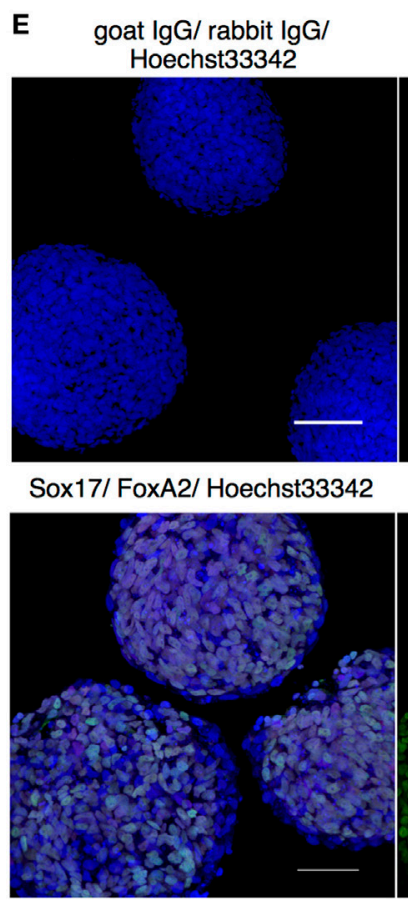

normal goat lgG

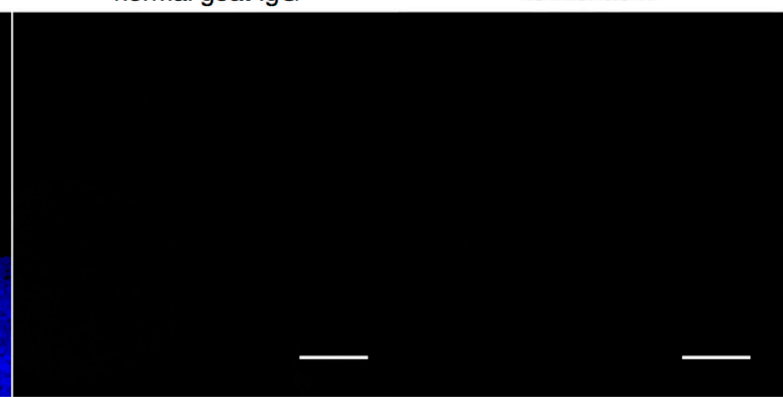

Sox17

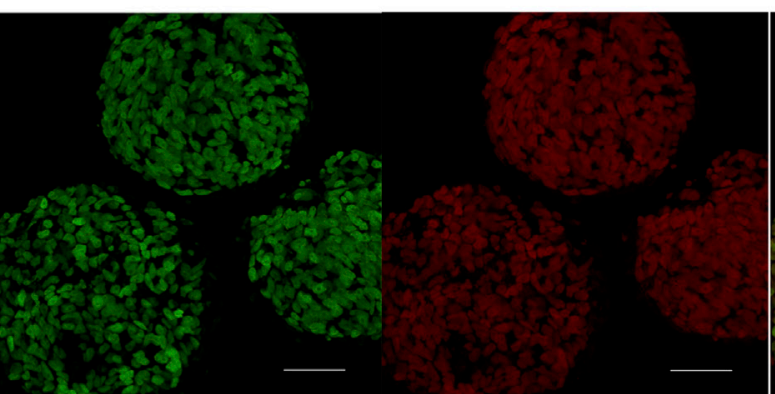

normal rabbit IgG-conjugated goat IgG/ rabbit lgG-conjugated to Alexa647

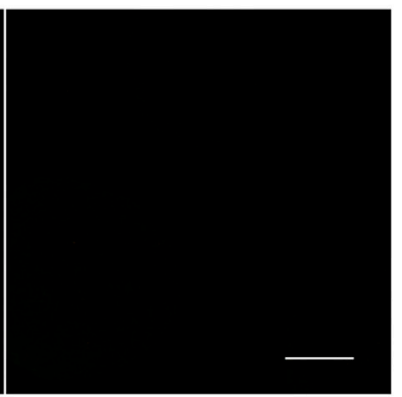

Sox17/ FoxA2

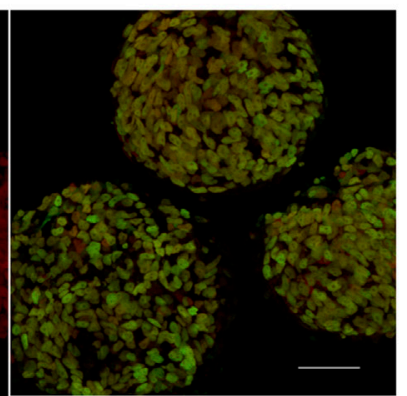

FIGURE 1 | Endodermal differentiation of human induced pluripotent stem cells (iPSCs). (A) Schematic diagram of the induction protocol for definitive endoderm production from human iPSCs. (B) Embryoid bodies (EBs) collected pre- and post-Activin A exposure, as observed by light microscopy on culture days 2, 5, and 20. Scale bar $=100 \mu \mathrm{m}$. (C) Real-time reverse-transcription polymerase chain reaction analysis of definitive endodermal markers. Significant differences in Sox17 were detected between EBs after Activin A exposure (culture day 5) and samples on culture day 0, day 15, and day 20. In addition, FoxA2 expression on day 5 was significantly increased in comparison with cultures on day 0 , and decreased with significant differences between those of day 15 and day 20. Bars indicate average percentage of Gapdh gene expression $\pm S D$; $\left({ }^{*} p<0.05,{ }^{* \star} p<0.01\right.$ versus day $\left.5, n=3\right)$. Statistical analysis was performed by one-way ANOVA and post hoc Tukey's test. (D) Percentage of Sox17- and FoxA2-expressing cells as counted by flow cytometry. After stimulation with Activin A for 3 days, the rate of Sox 17 and FoxA2 double-positive cells increased to more than $45 \%$, with a maximum of $58 \%$. Bars indicate average percentage of Sox17- and FoxA2-expressing cells \pm SD $(n=3)$. (E) Immunostaining of EBs on day 5 with anti-Sox17 and anti-FoxA2 antibodies. Images in the upper line present negative control. Images in the lower show Hoechst33342 for nuclei (blue) and Sox17 (green) and FoxA2 (red). Scale bar $=100 \mu \mathrm{m}$ in the upper line and $50 \mu \mathrm{m}$ in the lower.

differentiation and promotes the differentiation to TFCs after TSH treatment (15). As cells on day 20 co-expressed Pax8 and Nkx2-1 mRNA and protein (Figures 2A-C), we next examined whether these cells might possess characteristics of TFCs. Consistent with the previous report examining overexpression of Pax8 (15), Tshr and Nis were expressed in cells at day 5 to some extent, a feature accompanied by expression of $\operatorname{Pax} 8$ (Figures $2 \mathrm{~A}$ and 3A). Although expression of $\mathrm{Tg}$ and $T p o$ was not observed on day 5, it was observed thereafter until day 20 (Figure 3A). Immunostaining of differentiated cells on day 20 revealed expression of NIS surrounding the nuclei of NKX2-1 positive cells, and TSHR protein was expressed in many Nkx2-1-expressing cells (Figure 3B). Moreover, TSHR-positive cells gathered around cells expressing TG inside their cytoplasm (Figure $3 \mathbf{B}$ ). Secretion of thyroid hormone is the most important function of TFCs. Analysis of culture medium harvested 25 days after differentiation culture by ELISA showed significant increases in human-free $\mathrm{T}_{4}$ compared with control medium (differentiation culture medium not used for cultivation; $p<0.01$, Figure $3 \mathrm{C}$ ). These findings suggest 3-D suspension culture might successfully induce functional TFCs.

\section{DISCUSSION}

In the present study, we demonstrated the direct differentiation of TFCs from human iPSCs using defined factors in a scalable suspension culture method. Transient treatment with Activin A induced expression of Pax 8 and TSHR, whereas subsequent treatment with TSH induced the differentiation of TFCs expressing TG, TPO, TSHR, and NIS. Moreover, differentiated cells secreted free $\mathrm{T}_{4}$ in vitro.

Thyroid tissues are known to differentiate from definitive endoderm. As reported in a previous study of endoderm differentiation (21), treatment with Activin A and CHIR99021 induced Sox17- and FoxA2-expressing definitive endoderm cells in the present study. Surprisingly, we observed expression of Pax 8 and Tshr as early as the definitive endoderm stage (day 5). As several studies have reported promotion of Pax 8 and Nkx2-1 expression with Activin A treatment $(22,23)$, the essential role Activin A directly plays on differentiation of both endoderm and TFCs has been established in our study. Precise mechanisms underlying TSHR expression on day 5 remain unclear. However, as we observed a very small number of $N k x 2-1$-expressing cells on day 
5 and this transcription factor is known to bind to the promoter region of TSHR to promote expression (24), activation of Nkx2-1 by Activin A may also drive expression of TSHR on day 5. As thyroid placode cells co-express Pax8 and Nkx2-1 in the pharyngeal floor to be distinguished from other types of cells $(25,26)$, Pax8 and Nkx2-1 are particularly dealt with indispensable factors for morphogenesis of the thyroid gland (26-28) and estimating thyroid progenitors (29). Therefore, cells co-overexpressing Pax8 and Nkx2-1 have often been applied to study execution of thyroid gland development $(15,16,30)$. After treatment with TSH for 15 days (day 20 of culture), we confirmed abundant Pax8 and Nkx2-1 mRNA and protein expression, and about $15 \%$ of cells were positive for both Pax8 and Nkx2-1. These results indicate Pax 8 and Nkx2-1 are regulated by Activin A stimulation and
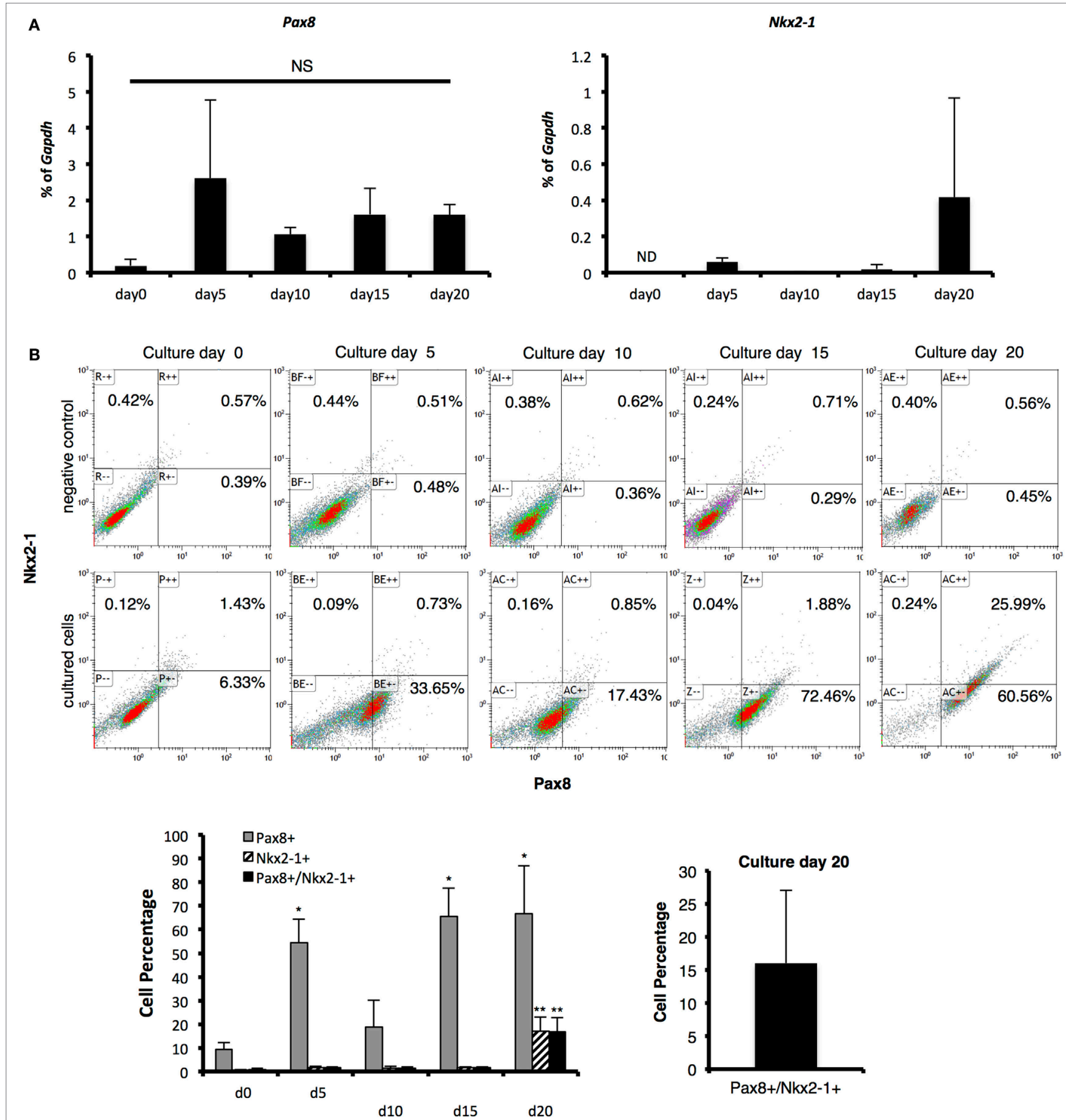

FIGURE 2 | Continued 


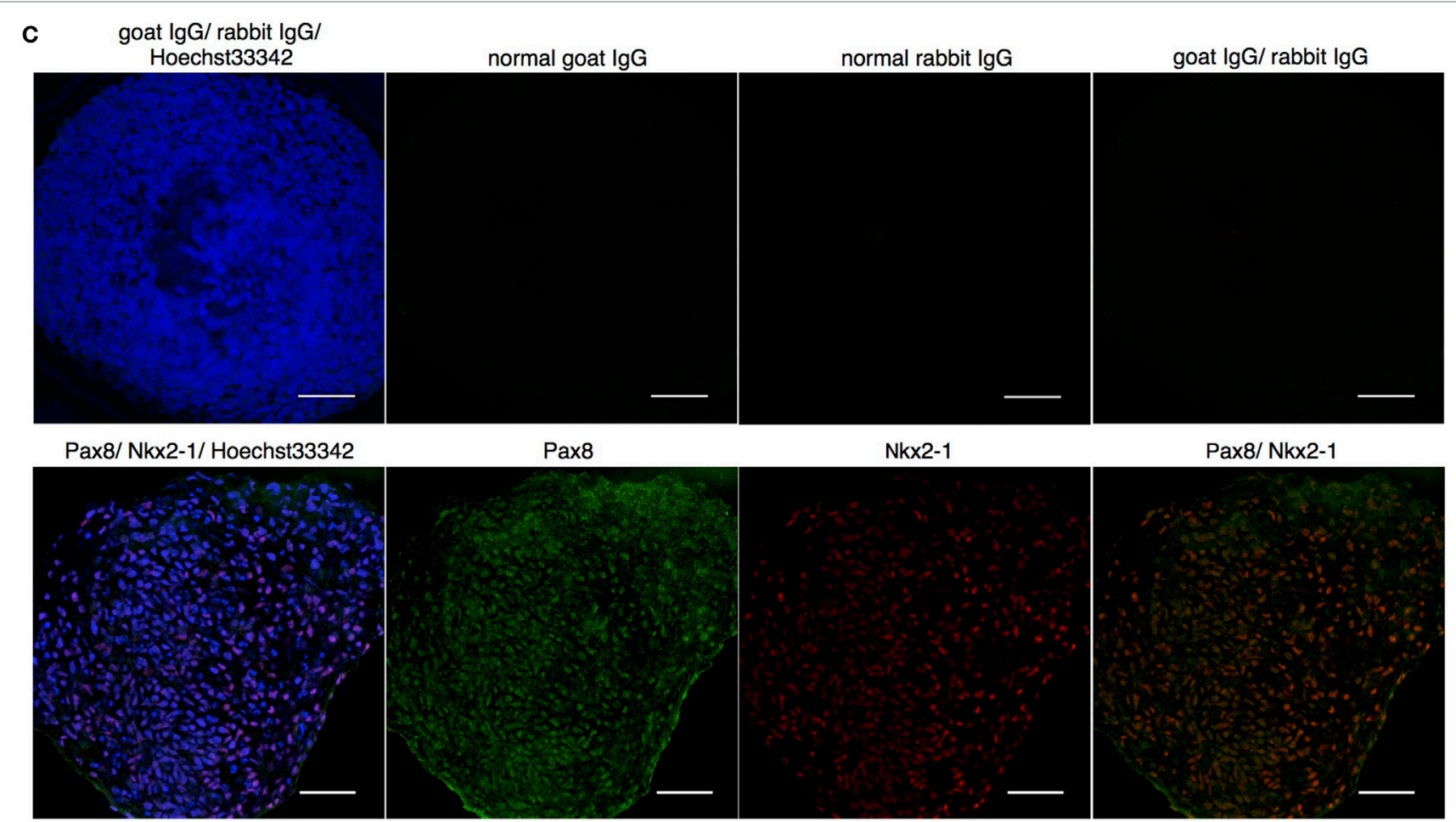

FIGURE 2 | Identification of thyroid transcription markers. (A) Pax8 and Nkx2-1 mRNA expression as measured with real-time reverse-transcription polymerase chain reaction. Levels of gene expression were normalized to Gapdh. Bars indicate average percentage of Gapdh gene expression \pm SD $(n=3)$. ND indicates mRNA expression was not detected and NS indicates not significant. There was no significant difference between all samples in Pax8 by ANOVA.

(B) Percentage of Pax8 and Nkx2-1 co-expressing cells as counted by flow cytometry. Pax8-positive cells increased in 5 days to more than $50 \%$, which was maintained until day 20, except for a transient decrease on day 10. Percentage of Pax8 and Nkx2-1 double-positive cells increased in a time-dependent manner, resulting in $16 \%$ approximately on culture day 20. Negative controls were applied for normal lgG instead of primary antibodies. Bars indicate average percentage of Pax8- and Nkx2-1-coexpressing cells \pm SD $(n=3)$. Statistical analysis was performed by one-way ANOVA. (C) Immunohistological analysis of Pax8 and Nkx2-1. Images in the upper line present negative controls. Images in lower show Pax8 (green), Nkx2-1 (red), and Hoechst33342 (blue). Scale bar = 50 um.
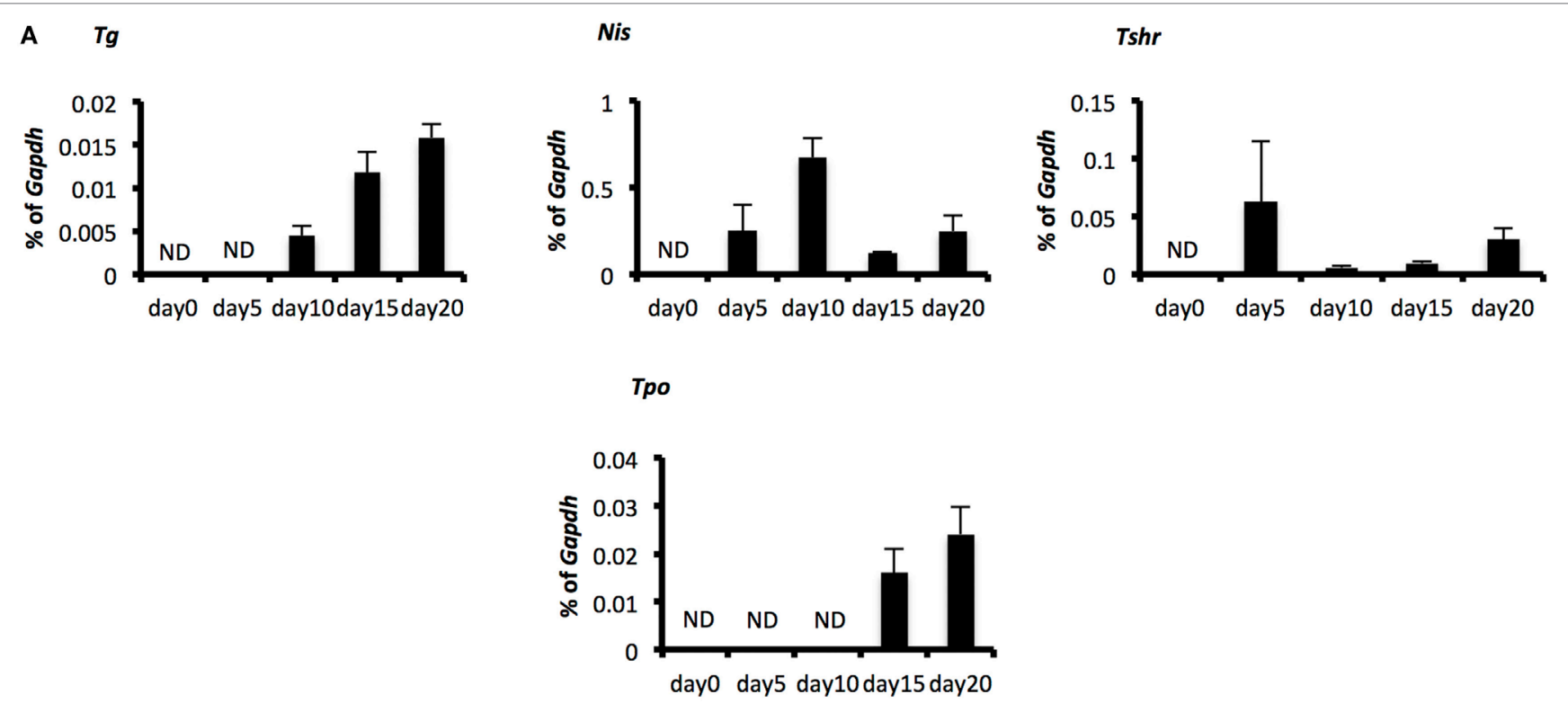

day0 day5 day10 day15 day20

FIGURE $3 \mid$ Continued 


\section{B rabbit lgG/ mouse lgG/ Hoechst33342}
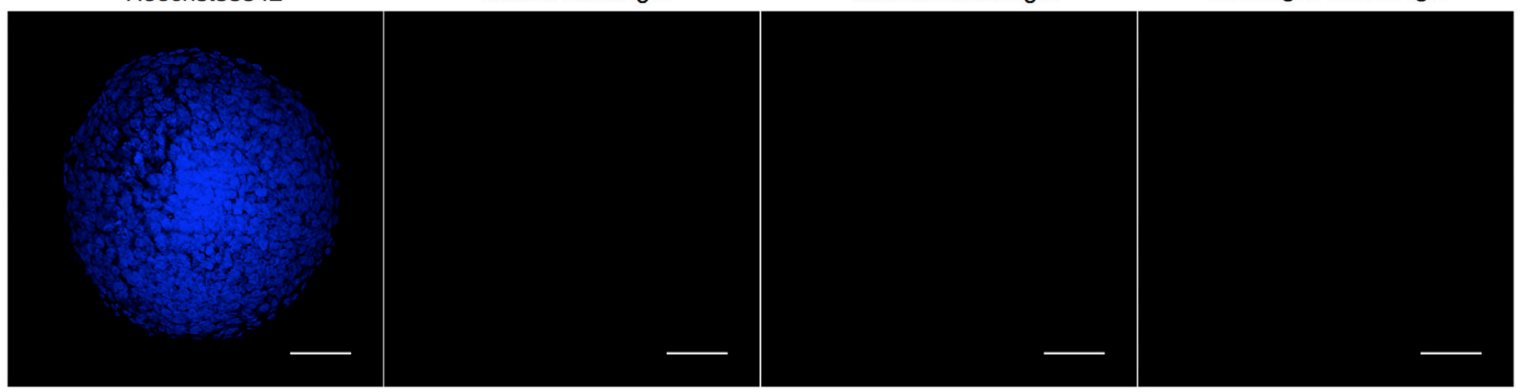

Nkx2-1/ TSHR/ Hoechst33342

Nkx2-1

TSHR

Nkx2-1/ TSHR
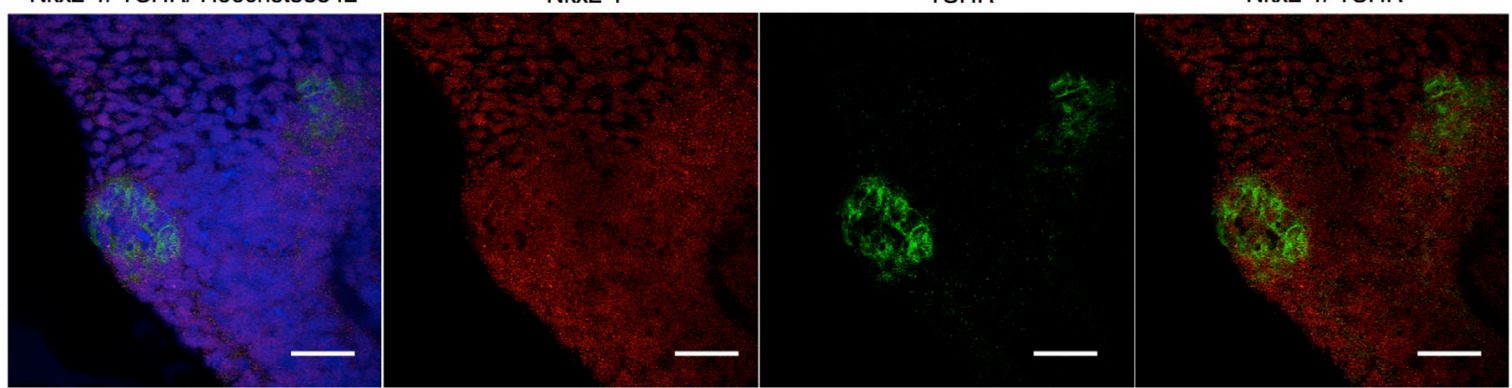

TNkx2-1/ NIS/ Hoechst33342

Nkx2-1

NIS

Nkx2-1/ NIS
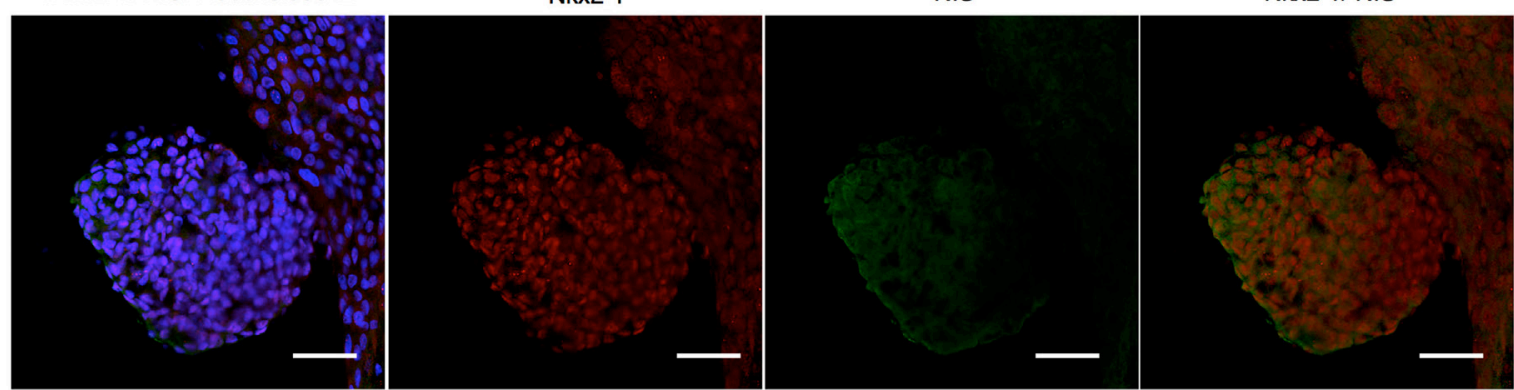

TG/ TSHR/ Hoechst33342

TG

TSHR

TG TSHR

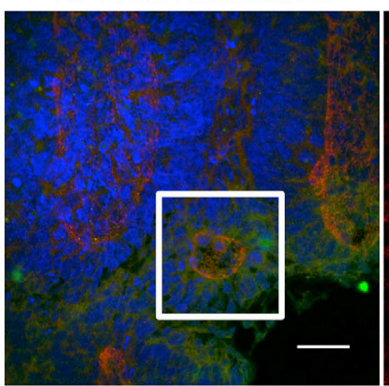

Enlarged

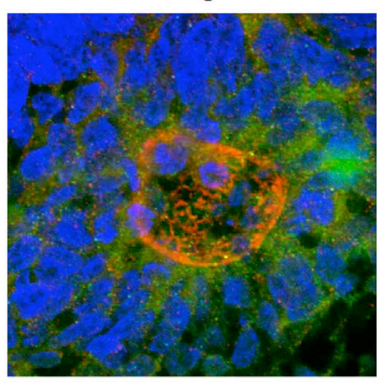

C

human free T4

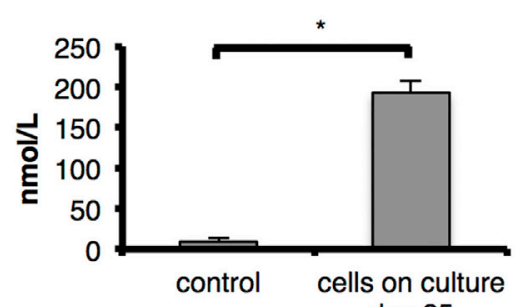

day 25

FIGURE $3 \mid$ Continued 
FIGURE 3 | Continued

Evaluation of thyroid specificity with characteristic thyroid markers on culture day 20 and measurement of free $\mathrm{T}_{4}$. (A) Levels of thyroid-specific mRNA expression. Bars indicate average percentage of Gapdh gene expression \pm SD $(n=3)$. ND, not-detected. (B) Immunostaining of embryoid bodies on day 20 with thyroid-specific markers NIS, thyroglobulin, and thyroid-stimulating hormone receptor. Images in the top line present negative controls. Scale bar $=50$ m in the top line, $30 \mu \mathrm{m}$ in the lower lines. (C) Levels of human-free $T_{4}$ were higher significantly in the cultured-cell medium than in the control medium ( ${ }^{*} p<0.01$ ). Control medium is thyroid-stimulating hormone-supplemented medium before cells were harvested. Bars indicate average-free $T_{4}$ levels $\pm \mathrm{SD}(n=3)$. Statistical analysis was performed by unpaired Student's $t$-test.

afterward controlled by the TSH/TSHR pathway. As known as an established fact, $\mathrm{Nkx} 2-1$ is expressed in the multiple kinds of tissues and cells, not only thyroid and parathyroid, but the fourth branchial pouch, ultimobranchial body, lung, posterior pituitary, hypothalamus, and trachea $(17,25,29)$. Though the current results showed that the percentage of Pax8-negative/ Nkx2-1-positive cells was rare, the possibility of the existence of respiratory endoderm or the restricted brain cells cannot be kicked out. As well, Pax8 expresses not only in the developing thyroid gland but kidneys and myelencephalon $(17,26,27,31)$ and plays an essential part in the folliculogenesis of the thyroid gland (12). Therefore, the most of the collected cells, Pax8-positive/ Nkx2-1-negative cells might include the developing kidney or neural tissue. At last, Pax8-negative/Nkx2-1-negative cells would include other than endodermal cells.

Expression of other TTFs, such as haematopoietically expressed homeobox (Hhex) and forkhead box E1 (FoxE1) proteins $(17,19)$, may modulate thyroid-specific genes along with TSH treatment. As expression of FoxE1 is strongly dependent upon Pax8 in thyroid progenitors (13), expression of Pax8 activated by the defined factors used in the present study might be sufficient to regulate transcription of other thyroid-specific genes.

Nkx2-1 is expressed not only in thyroid tissue but also in lung. Recent reports have reiterated the importance of a negative expression correlation between FoxA2 and Nkx2-1 for specification of thyroid tissues (19). Upregulation of Nkx2-1 accompanied by the downregulation of FoxA2 is important for thyroid development, while maintenance of FoxA2 expression in Nkx2-1-expressing cells is essential for lung development (32). In this study, we observed downregulation of FoxA2 after treatment with TSH, which contributed to the efficient differentiation of TFCs.

In the present study, we supplemented TSH in the culture medium to promote differentiation of TFCs from human iPSCs. However, the importance of TSH for thyroid development remains an open question. Some reports indicate subsequent treatment with TSH after transfection of Pax8 and Nkx2-1 promotes differentiation of mouse and human ESCs into functional thyroid cells $(15,16,23,30,33-36)$. More recently, Kurmann et al. reported that TSH treatment promoted the further differentiation of thyroid progenitor cells into functional TFCs in mouse and human ESCs without transfection of TTFs (37). In contrast, Postiglione et al. reported the development of normal-sized thyroid glands in both TSH-deprived and TSHR-knockout mice. However, expression of TPO and NIS was downregulated, suggesting that the TSH/TSHR pathway may be important to regulate TPO and NIS gene expression but is not essential for thyroid development in the mouse embryo (38). In this study, bimodal upregulation of TSHR expression was observed at day 5 and day 20. This trend might be enhanced by TTFs such as Pax8 and Nkx2-1 in this first 5 days. Meanwhile, subsequent TSH treatment may enhance TSHR expression along with upregulation of TTFs, potentially leading to the expression of genes related to thyroid maturation, including NIS, TPO, and TG, via reciprocal TSH/TSHR pathway activation. In the present study, we successfully observed the secretion of free $\mathrm{T}_{4}$ in differentiated TFCs in vitro. Though differentiated TFCs did not present typical follicle structures in vitro, as cells co-expressing TG and TSHR gathered inside EBs, we examined whether these cells could develop and mature into functional TFCs under folliculogenesis.

The thyroid gland maintains its characteristic honeycomb-like structure by organizing follicles gathered within its lining of follicular epithelial cells (2). Upon a review of the literature, TFCs have primarily been differentiated using traditional adherent culture methods on dishes $(33,34,36)$ or embedded in Matrigel ${ }^{\circledR}$ as a $3-\mathrm{D}$ environment $(14-16,32,37)$. One of the most unique points in our study of TFC induction is the adoption of 3-D stirred culture methods for all processes. We previously reported the effectiveness of 3-D suspension culture to produce large amounts of cardiomyocytes from human iPSCs, especially for its ease of scalability for cell proliferation (8). To supplement thyroid hormone levels associated with hypothyroidism, it has been estimated that more than $1 \times 10^{8}-1 \times 10^{10}$ TFCs are required per person $(5,39,40)$. Therefore, we anticipate utilizing bioreactor will contribute to regenerative medicine development for thyroid dysfunction by allowing effective production of a large enough number of TFCs. Though issues still remain for cell purification and tumorigenesis, at least with regard to organization of the thyroid gland, we previously succeeded in fabricating rat functional thyroid tissue using cell sheet tissue engineering (5). In the future, our combination of suspension culture and cell sheet technology will facilitate production of human iPSC-derived thyroids capable of rescuing hypothyroidism.

\section{AUTHOR CONTRIBUTIONS}

AA and KM conceived the study. AA performed the experiments and analyzed the data. AA, KM, TS, and TO wrote the manuscript.

\section{ACKNOWLEDGMENTS}

The authors thank Prof. Osamu Isozaki, MD, of the Department of Endocrinology at Tokyo Women's Medical University, for his useful comments about thyroid molecular biology, and Prof. Yoji Nagashima, in the Department of Pathology at Tokyo Women's Medical University, for his expertise in conducting pathohistology. 


\section{FUNDING}

This work was supported by JSPS KAKENHI Grant Number JP16K19561, the Formation of Innovation Center for Fusion

\section{REFERENCES}

1. Hermus AR, Huysmans DA. Treatment of benign nodular thyroid disease. N Engl J Med (1998) 338:1438-47. doi:10.1056/NEJM199805143382007

2. Young B, Phillip W, O'Dowd G. Wheater's Functional Histology: A Text and Colour Atlas. Philadelphia, PA: Elsevier Churchill Livingstone (2014). p. 323-5.

3. Yamada N, Okano T, Sakai H, Karikusa F, Sawasaki Y, Sakurai Y. Thermoresponsive polymeric surfaces; control of attachment and detachment of cultured cells. Makromol Chem Rapid Commun (1990) 11:571-6. doi:10.1002/ marc.1990.030111109

4. Yamato M, Okano T. Cell sheet engineering. Mater Today (2004) 7:42-7. doi:10.1016/s1369-7021(04)00234-2

5. Arauchi A, Shimizu T, Yamato M, Obara T, Okano T. Tissue-engineered thyroid cell sheet rescued hypothyroidism in rat models after receiving total thyroidectomy comparing with nontransplantation models. Tissue Eng Part A (2009) 15:3943-9. doi:10.1089/ten.TEA.2009.0119

6. Takahashi K, Tanabe K, Ohnuki M, Narita M, Ichisaka T, Tomoda K, et al. Induction of pluripotent stem cells from adult human fibroblasts by defined factors. Cell (2007) 131:861-72. doi:10.1016/j.cell.2007.11.019

7. Nakagawa M, Koyanagi M, Tanabe K, Takahashi K, Ichisaka T, Aoi T, et al. Generation of induced pluripotent stem cells without Myc from mouse and human fibroblasts. Nat Biotechnol (2008) 26:101-6. doi:10.1038/nbt1374

8. Matsuura K, Wada M, Shimizu T, Haraguchi Y, Sato F, Sugiyama K, et al. Creation of human cardiac cell sheets using pluripotent stem cells. Biochem Biophys Res Commun (2012) 425:321-7. doi:10.1016/j.bbrc.2012.07.089

9. Komae H, Sekine H, Dobashi I, Matsuura K, Ono M, Okano T, et al. Three-dimensional functional human myocardial tissues fabricated from induced pluripotent stem cells. J Tissue Eng Regen Med (2015) 11(3):926-35. doi:10.1002/term.1995

10. Martinez Barbera JP, Clements M, Thomas P, Rodriguez T, Meloy D, Kioussis D, et al. The homeobox gene Hex is required in definitive endodermal tissues for normal forebrain, liver and thyroid formation. Development (2000) 127:2433-45.

11. Kimura S, Ward JM, Minoo P. Thyroid-specific enhancer-binding protein/ thyroid transcription factor 1 is not required for the initial specification of the thyroid and lung primordia. Biochimie (1999) 81:321-7. doi:10.1016/ S0300-9084(99)80077-7

12. Mansouri A, Chowdhury K, Gruss P. Follicular cells of the thyroid gland require Pax8 gene function. Nat Genet (1998) 19:87-90. doi:10.1038/ng0598-87

13. Parlato R, Rosica A, Rodriguez-Mallon A, Affuso A, Postiglione MP, Arra C, et al. An integrated regulatory network controlling survival and migration in thyroid organogenesis. Dev Biol (2004) 276:464-75. doi:10.1016/j.ydbio. 2004.08.048

14. Antonica F, Kasprzyk DF, Opitz R, Iacovino M, Liao XH, Dumitrescu AM, et al. Generation of functional thyroid from embryonic stem cells. Nature (2012) 491:66-71. doi:10.1038/nature11525

15. Ma R, Latif R, Davies TF. Human embryonic stem cells form functional thyroid follicles. Thyroid (2015) 25:455-61. doi:10.1089/thy.2014.0537

16. Ma R, Morshed SA, Latif R, Davies TF. Thyroid cell differentiation from murine induced pluripotent stem cells. Front Endocrinol (2015) 6:56. doi:10.3389/ fendo.2015.00056

17. Fernandez LP, Lopez-Marquez A, Santisteban P. Thyroid transcription factors in development, differentiation and disease. Nat Rev Endocrinol (2015) 11: 29-42. doi:10.1038/nrendo.2014.186

18. D’Amour KA, Agulnick AD, Eliazer S, Kelly OG, Kroon E, Baetge EE. Efficient differentiation of human embryonic stem cells to definitive endoderm. Nat Biotechnol (2005) 23:1534-41. doi:10.1038/nbt1163

19. Fagman H, Amendola E, Parrillo L, Zoppoli P, Marotta P, Scarfò M, et al. Gene expression profiling at early organogenesis reveals both common and diverse mechanisms in foregut patterning. Dev Biol (2011) 359:163-75. doi:10.1016/ j.ydbio.2011.08.015 of Advanced Technologies in the Special Coordination Funds for Promoting Science and Technology "Cell Sheet Tissue Engineering Center," Japan, and Yamakawa Prize estimated in Tokyo Women's Medical University.

20. Green MD, Chen A, Nostro MC, D’Souza SL, Schaniel C, Lemischka IR, et al. Generation of anterior foregut endoderm from human embryonic and induced pluripotent stem cells. Nat Biotechnol (2011) 29:267-72. doi:10.1038/ nbt1788

21. Kunisada Y, Tsubooka-Yamazoe N, Shoji M, Hosoya M. Small molecules induce efficient differentiation into insulin-producing cells from human induced pluripotent stem cells. Stem Cell Res (2012) 8:274-84. doi:10.1016/j. scr.2011.10.002

22. Li Y, Eggermont K, Vanslembrouck V, Verfaillie CM. NKX2-1 activation by SMAD2 signaling after definitive endoderm differentiation in human embryonic stem cell. Stem Cells Dev (2013) 22:1433-42. doi:10.1089/scd.2012.0620

23. Ma R, Latif R, Davies TF. Thyrotropin-independent induction of thyroid endoderm from embryonic stem cells by activin A. Endocrinology (2009) 150:1970-5. doi:10.1210/en.2008-1374

24. García-Jiménez C, Santisteban P. TSH signalling and cancer. Arq Bras Endocrinol Metabol (2007) 51:654-71. doi:10.1590/S0004-27302007000500003

25. Lazzaro D, Price M, de Felice M, Di Lauro R. The transcription factor TTF-1 is expressed at the onset of thyroid and lung morphogenesis and in restricted regions of the foetal brain. Development (1991) 113:1093-104.

26. Plachov D, Chowdhury K, Walther C, Simon D, Guenet JL, Gruss P. Pax8, a murine paired box gene expressed in the developing excretory system and thyroid gland. Development (1990) 110:643-51.

27. Pasca di Magliano M, Di Lauro R, Zannini M. Pax8 has a key role in thyroid cell differentiation. Proc Natl Acad Sci U S A (2000) 97:13144-9. doi:10.1073/ pnas. 240336397

28. Di Palma T, Filippone MG, Pierantoni GM, Fusco A, Soddu S, Zannini M. Pax8 has a critical role in epithelial cell survival and proliferation. Cell Death Dis (2013) 4:e729. doi:10.1038/cddis.2013.262

29. Longmire TA, Ikonomou L, Hawkins F, Christodoulou C, Cao Y, Jean JC, et al. Efficient derivation of purified lung and thyroid progenitors from embryonic stem cells. Cell Stem Cell (2012) 10:398-411. doi:10.1016/j.stem. 2012.01.019

30. Ma R, Latif R, Davies TF. Thyroid follicle formation and thyroglobulin expression in multipotent endodermal stem cells. Thyroid (2013) 23:385-91. doi:10.1089/thy.2012.0644

31. Zannini M, Avantaggiato V, Biffali E, Arnone MI, Sato K, Pischetola M, et al. TTF-2, a new forkhead protein, shows a temporal expression in the developing thyroid which is consistent with a role in controlling the onset of differentiation. EMBO J (1997) 16:3185-97. doi:10.1093/emboj/16.11.3185

32. Dame K, Cincotta S, Lang AH, Sanghrajka RM, Zhang L, Choi J, et al. Thyroid progenitors are robustly derived from embryonic stem cells through transient, developmental stage-specific overexpression of Nkx2-1. Stem Cell Reports (2017) 8:216-25. doi:10.1016/j.stemcr.2016.12.024

33. Arufe MC, Lu M, Kubo A, Keller G, Davies TF, Lin RY. Directed differentiation of mouse embryonic stem cells into thyroid follicular cells. Endocrinology (2006) 147:3007-15. doi:10.1210/en.2005-1239

34. Arufe MC, Lu M, Lin RY. Differentiation of murine embryonic stem cells to thyrocytes requires insulin and insulin-like growth factor-1. Biochem Biophys Res Commun (2009) 381:264-70. doi:10.1016/j.bbrc.2009.02.035

35. Marians RC, Ng L, Blair HC, Unger P, Graves PN, Davies TF. Defining thyrotropin-dependent and -independent steps of thyroid hormone synthesis by using thyrotropin receptor-null mice. Proc Natl Acad Sci U S A (2002) 99:15776-81. doi:10.1073/pnas.242322099

36. Lin RY, Kubo A, Keller GM, Davies TF. Committing embryonic stem cells to differentiate into thyrocyte-like cells in vitro. Endocrinology (2003) 144: 2644-9. doi:10.1210/en.2002-0122

37. Kurmann AA, Serra M, Hawkins F, Rankin SA, Mori M, Astapova I, et al. Regeneration of thyroid function by transplantation of differentiated pluripotent stem cells. Cell Stem Cell (2015) 17:527-42. doi:10.1016/j.stem. 2015.09.004

38. Postiglione MP, Parlato R, Rodriguez-Mallon A, Rosica A, Mithbaokar P, Maresca $\mathrm{M}$, et al. Role of the thyroid-stimulating hormone receptor signaling 
in development and differentiation of the thyroid gland. Proc Natl Acad Sci U S A (2002) 99:15462-7. doi:10.1073/pnas.242328999

39. Domann FE, Mitchen JM, Clifton KH. Restoration of thyroid function after total thyroidectomy and quantitative thyroid cell transplantation. Endocrinology (1990) 127:2673-8. doi:10.1210/endo-127-6-2673

40. Okamoto T, Fujimoto Y, Obara T, Ito Y, Kodama T, Kusakabe K. Trial of thyroid autotransplantation in patients with Graves' disease whose remnant thyroid has unintentionally been made too small at subtotal thyroidectomy. Endocrinol Jpn (1990) 37:95-101. doi:10.1507/endocrj1954.37.95

Conflict of Interest Statement: TO is a founder and director of the board of CellSeed Inc., which licenses technologies and patents from Tokyo Women's
Medical University. TO is also a shareholder of CellSeed Inc., Tokyo Women's Medical University and is receiving research funds from CellSeed Inc. TO, TS, and $\mathrm{KM}$ are inventors of bioreactor systems. Tokyo Women's Medical University, TO, TS, and KM receive a license fee from ABLE Corporation.

Copyright (c) 2017 Arauchi, Matsuura, Shimizu and Okano. This is an open-access article distributed under the terms of the Creative Commons Attribution License (CC BY). The use, distribution or reproduction in other forums is permitted, provided the original author(s) or licensor are credited and that the original publication in this journal is cited, in accordance with accepted academic practice. No use, distribution or reproduction is permitted which does not comply with these terms. 